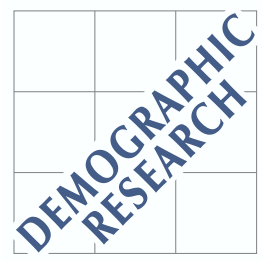

Demographic Research a free, expedited, online journal of peer-reviewed research and commentary in the population sciences published by the Max Planck Institute for Demographic Research Konrad-Zuse Str. 1, D-18057 Rostock · GERMANY www.demographic-research.org

DEMOGRAPHIC RESEARCH

VOLUME 23, ARTICLE 12, PAGES 335-364 PUBLISHED 10 AUGUST 2010

http://www.demographic-research.org/Volumes/Vol23/12/

DOI: $\quad$ 10.4054/DemRes.2010.23.12

Research Article

\title{
Contraceptive use and intent in Guatemala
}

\section{Kathryn Grace}

(c) 2010 Kathryn Grace.

This open-access work is published under the terms of the Creative Commons Attribution NonCommercial License 2.0 Germany, which permits use, reproduction \& distribution in any medium for non-commercial purposes, provided the original author(s) and source are given credit. See http://creativecommons.org/licenses/by-nc/2.0/de/ 


\section{Table of Contents}

1 Introduction 336

$2 \quad$ Contraceptive dynamics in Guatemala 336

3 Data 338

$4 \quad$ Methods 339

4.1 Modeling contraceptive use and intent 341

$5 \quad$ Results 346

$\begin{array}{lll}5.1 & \text { Descriptive analysis } & 346\end{array}$

$\begin{array}{llr}5.2 & \text { Trees } & 350\end{array}$

6 Discussion 355

$7 \quad$ Conclusion $\quad 357$

$8 \quad$ Acknowledgments 358

References 


\title{
Contraceptive use and intent in Guatemala
}

\author{
Kathryn Grace ${ }^{1}$
}

\begin{abstract}
Guatemala is characterized by low contraceptive use rates and one of the highest fertility rates in the Western Hemisphere. These rates are particularly extreme for the poorest segment of the population and for the indigenous population. However, notable increases in contraceptive use have occurred within the past ten years, indicating that Guatemala may be on the precipice of significant demographic change. The purpose of this research is to enhance understanding of the modern contraceptive revolution in Guatemala through identification of the segments of the Guatemalan population at most need for contraceptive and family planning services. Using the most recently available survey data, the 2002 Reproductive Health Survey data set (RHS), classification trees are used to determine the women with greatest need for reproductive health services. The results highlight the persistent marginalization of the poor and the indigenous and provide further insight into the impact of education, place of residence and couple characteristics on contraceptive use and intent.
\end{abstract}

\footnotetext{
${ }^{1}$ University of California at Santa Barbara. E-mail: grace@geog.ucsb.edu. This work was conducted, in part, while the author was a postdoctoral researcher at the Max Planck Institute for Demographic Research, Rostock.
} 


\section{Introduction}

Much of Latin America has recently experienced a rapid decline in fertility accelerated by an increase in contraceptive use (PRB 2007). An increasing number of countries in both Central and South America are characterized by below replacement total fertility rates (TFR) and contraceptive prevalence rates (CPR) matching those of more developed countries (De Broe and Hinde 2006; PRB 2007; Rosero-Bixby, Martin, and Martin-Garcia 2008). However, a closer look at country and regional family planning behavior in Latin America reveals exceptional subgroups with unusually high TFR and correspondingly low CPR. Once a leader in family planning, and despite recent strides in contraceptive expansion and fertility decline, Guatemala has the highest TFR in Latin America and one of the lowest CPRs in the Western Hemisphere (Santiso-Galvez and Bertrand 2004; De Broe and Hinde 2006; PRB 2007). In a context where maternal and infant mortality rates are high, poverty is rampant, and malnutrition is common, empowering women with the knowledge and resources to plan their own families is vital. However, Guatemala's low CPR and high TFR suggest that the ability of women to freely determine the timing and number of births may be limited.

The goal of this research is to identify the Guatemalan women with the greatest need for contraceptive services using the most recently ${ }^{3}$ collected data. The results of the analysis aim to provide information helpful to monitoring Guatemala's evolving contraceptive needs and documenting the fertility transition in a contemporary less developed country. Differing from related research, this study incorporates flexible modeling techniques, the most recent data, and includes an alternative approach to ethnic classification. The results of the research therefore contribute to an improved general understanding of contraceptive dynamics in one of the fastest growing and most impoverished countries in Latin America.

\section{Contraceptive dynamics in Guatemala}

Concern about the reproductive health of poor Guatemalan women motivated the 1964 development of the Asociación ProBienestar de la Familia (Federation of Family Well-being [APROFAM]) (Santiso-Galvez and Bertrand 2004). Supported by the International Planned Parenthood Association, APROFAM began building reproductive

\footnotetext{
${ }^{3}$ Unfortunately, data from 2002 are the most currently available national level data for Guatemala. While the data may be somewhat outdated, they represent the population at a time immediately following expansion of governmental family planning services and indications of declining fertility. However, since fertility was high and contraceptive use low this period is likely an early stage in Guatemala's fertility transition. The importance of understanding modern fertility transitions in the developing world lends support to the use of older data when necessary, as in this case.
} 
health clinics the following year. Shortly after the first clinic was established, Guatemala was identified, in terms of women's health, as one of only a handful of forward-thinking Latin American countries (Hall 1973; Santiso-Galvez and Bertrand 2004). However, the combined impact of the civil war (1960-1996) with other socio-demographic factors caused significant stagnation in the country-wide adoption of family planning. Guatemala's unstable and, at times, violent social and political climate are theorized to be the root causes of the "delayed contraceptive revolution" and have resulted in a limited supply and demand for contraception (Santiso-Galvez and Bertrand 2004; De Broe and Hinde 2006).

According to the most recent reports, Guatemala ranks the lowest in overall contraceptive use among the neighboring Central American countries of El Salvador, Honduras and Nicaragua. The 2002 ENSMI $^{4}$ reports a use rate of $43.3 \%$ among women in union - almost $20 \%$ lower than Honduras, the country with the second lowest recorded rate. Across Guatemala's eight political regions significant variation in contraceptive use complicates a straight-forward country-level increase in use. With a high value of $60 \%$ the Metropolitan region's CPR perhaps reflects the impact of urbanization, modern values (including "modern" attitudes towards women's education and labor force participation), economic development and access to services on contraceptive use - while the low value of $27 \%$ for the Northwest region suggests that either the women of this region maintain traditionally large family size goals or are unable to access contraceptive technology (Bertrand, Seiber, and Escudero 2001). When characterized by age - only $23 \%$ of women in union aged 15-19 and 35\% of women aged 20-24 report use of contraception. Again, these are the lowest age-specific use rates among the four neighboring Central American countries - more than $30 \%$ lower than Nicaragua's rates and about $20 \%$ lower than those of Honduras.

Researchers have also noted that rates of use are particularly low among the indigenous population (Bertrand, Seiber, and Escudero 2001; De Broe and Hinde 2006). The reasons underlying the low contraceptive use and high fertility rates likely reflect the complex history and social and economic stratification in Guatemala. Indigenous women traditionally have limited Spanish language skills and, as Spanish is the dominant language and frequently the only language spoken in health clinics, indigenous women may consequently have reduced access to reproductive health services. Indigenous women also have larger ideal family sizes and lower education rates - factors which may inhibit fertility regulation (Pebley, Delgado, and Brineman 1979; Bertrand, Seiber, and Escudero 2001; Pebley, Goldman, and Robles 2005; De Broe and Hinde 2006). Because Guatemala is

\footnotetext{
${ }^{4}$ Encuesta Nacional de Salud Materno Infantile (the National Survey of Maternal/Child Health) is a national Reproductive Health Survey (RHS) collected with the support of the US Centers for Disease Control.
} 
nearly $50 \%$ indigenous, of which the majority are poor, the impact of low contraceptive use has lasting implications for the health and economic development of the entire country.

In addition to low $\mathrm{CPR}$, Guatemalan women also report the lowest rate of intent to use contraception in Central America. While the intent to use rate is a measure of potential use or demand for contraception (Curtis and Westoff 1996), evaluating the characteristics of women who intend to use contraception can also provides some insight into barriers to contraception as well as underlying motivations of the demand for contraception. Therefore, despite the fact that use rates are comparatively low in Guatemala, a large or increasing portion of the population with an intention to use contraception may signal increasing contraceptive use and decreasing fertility levels in the near future. Only $41 \%$ of non-contracepting Guatemalan women in union report an intent to use contraception as compared to $71 \%$ in Honduras, $61 \%$ in Nicaragua and $49 \%$ in El Salvador. Thus, despite the low CPR, the majority of Guatemalan women who are not using contraception do not intend to use contraception now or in the future. Currently no research has evaluated which sub-groups of Guatemalan women intend to use contraception and therefore it is not clear if low intent reflects low demand or reflects barriers to family planning service attainment. Ensuring that women with an intent to use contraception have access to services could have an important impact on overall contraceptive use in Guatemala, while examining the differences between women with an intent and those without may provide further insight into Guatemala's evolving contraceptive demand and help to fine-tune the expansion of reproductive health programs in the region.

\section{Data}

Data from the 2002 ENSMI will be used to conduct the analysis (MSPAS 2002). The data were gathered with the technical assistance of the Centers for Disease Control and Prevention (CDC) as part of the Reproductive Health Surveys (RHS) program of the CDC. The data were collected randomly based on a stratified sampling scheme and each individual is assigned a weight. The weights were calculated based on a probabilistic sampling design of randomly selected households within randomly selected areas (based on the geographic areas used for population census data) and are adjusted to account for multiple eligible women within a household. The ENSMI report contains detailed information on the sampling strategy and on the departmental and regional weights.

The survey contains data from 9,155 Guatemalan women between the ages of 15 and 49. To incorporate the 2002 survey weights into the analysis, observations were replicated proportional to the weight such that the smallest fractional weight was equal to a single observation. This resulted in a self-weighting data set with 150,000 records. That data was 
then sampled to yield 10,000 records so as to not overstate the precision of the resulting estimates. In a comparison of the original weighted CDC data to the equally weighted sample of 10,000 average age, education, parity, and regional representation are almost identical. Based on the similarities in the relevant characteristics of the two populations, there is no indication that there is any significant difference between the original weighted sample or the constructed self-weighted sample.

\section{Methods}

Beyond the use of the most current data, this analysis differs from earlier analyses of Guatemala's contraceptive dynamics through the use of classification modeling techniques. Classification trees are a non-parametric technique designed to sort data in terms of the dependent variable into mutually exclusive categories based on the effective categorization of the independent variables. Trees have been used in public health research to identify at-risk populations and are valued for their ability to capture conditional relationships (to "describe associations in the data" (Lemon et al. 2003)) rather than to test the significance of variables on the response (see Lemon et al. 2003) for a detailed list of instances where trees have been used). Despite extensive analyses of family planning correlates, however, trees have not been applied in contraceptive use analyses and the utility of these models in family planning research is unexplored. In reference to Guatemala, where there is a long history of family planning research and yet a persistently low rate of contraceptive use, tree models may identify at-risk populations not captured by traditional regression techniques. The results may therefore help to provide researchers and policy makers with more nuanced information on the specific Guatemalan sub-groups at greatest need for the limited family planning resources. Tree models of use versus non-use and intention versus no-intention among Guatemalan women using the most recently collected country-level data will be constructed.

The model is constructed as the tree splits the data into the groups of the response variables. In this case we produce two trees, contraceptive use - yes or no and intent to use - yes or no. The variable that causes the most effective split, as measured by an entropy (measure of similarity) calculation (in this case the Gini coefficient ${ }^{5}$ is used), initiates the tree. The optimal split maintains the highest possible level of homogeneity - the variable that produces the smallest Gini coefficient in the daughter nodes that contain the split data (Ambalavanan et al. 2006). For example, in the case that only two splitting variables, ethnicity and union status, are used for grouping contraceptive users

5 The Gini coefficient is a measure of similarity. The calculation is straightforward: Gini $=1-\sum_{i} p_{i}^{2}$ where $p$ is the observed proportion of each type $i$. When evaluating ethnicity, for example, when $75 \%$ of a population is indigenous the Gini coefficient is lower than when half the population is indigenous. 
and non users then the number of users would be tallied and the Gini coefficient would be calculated according to each variable. If the sum of the nodal Gini coefficient values is smaller (indicating that on average the nodes are more homogeneous) when splitting along ethnicity as opposed to union then ethnicity becomes the first splitting variable. The splitting and entropy calculation process continues at each node of the tree using each of the independent variables (Nelson et al. 1998; Ambalavanan et al. 2006). The tree finally stops growing once perfect homogeneity is obtained or stopping rules are met (Lemon et al. 2003; Ambalavanan et al. 2006). At this point the analyst selects the ideal tree based on parsimony and efficiency in categorization.

Similar to an overparameterized regression, a "perfect" tree can be fit but it would be too cumbersome and unstable to be of any value. Model specification testing to achieve parsimony employs cross-validation using an a priori randomly selected portion of the data set. The cross-validation measure is calculated at each split and is adjusted to reflect the added complication brought in by additional variables (similar to adjusting the R-square in a regression). I used a combination of the cross-validation error and the number of factors in the tree to select the best tree among the universe of trees. The final tree was selected from the set of trees that was small enough to be interpretable but large enough to successfully categorize the sample. ${ }^{6}$ Terminal nodes in these pruned trees can therefore be interpreted as representing one level of the two-level response variable. ${ }^{7}$ The final terminal nodes represent categorization that is as near perfect homogeneity as possible within the confines of the a priori stopping rules. In the results presented here gray or pink shading is used to distinguish the terminal nodes from the daughter nodes.

Classification trees are able to incorporate a large number of independent variables and to identify complex interactions among variables. These are not characteristics of logistic regression and are among the primary reasons for using classification analysis instead of regression modeling. Frequently logistic regression models tend to be fitted with only marginal effects with the occasional addition of specific two-way effects. Higher order interactions tend to be omitted because they are difficult to interpret and present, even for experienced analysts. These issues are irrelevant in tree building as higher order interactions between variables are easy to identify and interpret. These benefits enable the analyst to explore varied factors that may have a potential effect on the outcome with virtually no limitations on the structure of the independent variables. The tree analysis scheme creates cut-off values for continuous independent variables and has the potential

\footnotetext{
${ }^{6}$ Almost identical trees were created with the use of the standard deviation technique. This technique selects the smallest tree with a misclassification error within one standard deviation of the tree with the smallest misclassification error (see Lemon et al. (2003) for more details).

7 This is similar to logistic regression where a cut-off percentage is established which groups continuous response values into one of two categories. This is the standard method used in regression to determine the predicted categorical outcome of an individual observation.
} 
to group the different levels of categorical variables for the purpose of creating an effective splitting node (Nelson et al. 1998).

In terms of accessibility, trees are an improvement on regression models. The usefulness of the regression model is restricted by the relatively small population of scientists and researchers with the training to interpret them. The classification tree's natural flow-chart style enables quick and easy model interpretability by a broad group of interested individuals (Faraway 2006; Martin et al. 2006). The inferential framework of logistic regression, on the other hand, emphasizes assessment and interpretation from estimated parameters, concepts which are unfamiliar to policy and health professionals.

Despite the flexibility of trees, as with all quantitative analyses it is still necessary to ground the selected independent variables in theory and to hypothesize about their relationship with the response variable. The following sub-section introduces the variables and the theories supporting their use.

\subsection{Modeling contraceptive use and intent}

Models based on two dichotomous dependent variables, contraceptive use (yes/no) and intent to use (yes/no) will be developed to evaluate current trends in contraceptive behavior. While an understanding of the characteristics of contraceptive users can help identify population groups who may be at need for services, developing an understanding of the characteristics of women with intent to use may provide further insight into the nuances of contraceptive use and may provide insight into demand and future use.

The independent variables used to model contraceptive use and intent in Guatemala have been selected based on the significance of related variables in similar research. The independent variables were classified in three categories: 1) Woman's characteristics, 2) Housing characteristics, and 3) Family/Relationship characteristics.

Woman's characteristics: This group of variables contains factors specific to each woman in the sample. Age and educational attainment are standard control variables in family planning analyses and are therefore implemented here. Age is categorized into seven groups, consistent with the standard five-year groupings, noting that the use of age as a categorical variable would facilitate the comparison of cohort behavior. Education is included as a three-level variable: no education, some primary, some secondary (or beyond). Secondary school generally begins at around age 12, before the majority of Guatemalan women enter into sexual relationships (Grace and Sweeney 2009) and has a positive effect on contraceptive use (Bertrand, Seiber, and Escudero 2001; De Broe and Hinde 2006).

It is important to note however, that educational attainment is complex in Guatemala. The indigenous population may face significant barriers to obtaining a formal education. For indigenous children to succeed in a typical Guatemalan classroom, they must develop 
adequate Spanish language skills. This may be particularly challenging if the child has limited exposure to spoken or written Spanish at home. Moreover, the extra costs of attending school may be prohibitive, as many schools require that the parents purchase materials and uniforms. The analysis strategy proposed for this research allows for the exploration of relationships between education, ethnicity and economic status. Exploring the education variable with regard to its relationship with the independent and dependent variables will aid in determining the actual role that women's education plays in reproductive health in this context.

Two variables, a religious identifier (Catholic, Protestant, or other) and an ethnicity variable, have been constructed to capture differences in behavior between groups. Catholicism has had a negative impact on contraceptive use expansion and family size goals throughout the world (Cutright, Hout, and Johnson 1976; Herold et al. 1989; Martine 1996; McQuillan 2004) and may have had a negative impact on contraceptive use in Guatemala (Terborgh et al. 1995; Santiso-Galvez and Bertrand 2004). However, within the last quarter century Protestantism has spread in Guatemala and more women now identify themselves as Protestants than in the past (MSPAS 2002). Traditionally the Catholic church is linked to a more pronatalist position yet Protestant groups encourage certain gender roles and behaviors which are also consistent with reduced contraceptive use and larger families (Wilson 1999). Each woman is therefore categorized as Catholic, Protestant, or other with the expectation that women who are Catholic or Protestant may be less likely to use or intend to use birth control.

Related research has indicated a link between fertility behavior, contraceptive use and ethnicity in Guatemala (Anderson et al. 1980; Terborgh et al. 1995; Shah, Shah, and Radovanovic 1998; Santiso-Galvez and Bertrand 2004; De Broe et al. 2005). As mentioned previously in the paper, contraceptive use is significantly lower among the indigenous population. Indigenous women are generally perceived as facing greater obstacles to contraceptive access and implementation due to social, economic or cultural barriers. Historically indigenous women are distinguished from Ladino (the Guatemalan term describing those of mixed European ancestry) women by their traditional clothing and Mayan-based language (contrasted with Ladino women who dress in western clothing and speak Spanish). Three factors were used to create an ethnicity variable; ethnic survey identification, maternal language, and language of the interview. Women who self-identified as indigenous ${ }^{8}$, whose interview was conducted in an indigenous language, and whose maternal language was not Spanish were given a score of zero and are considered indigenous. A woman who was categorized in the original data as Ladino, whose maternal language was Spanish (indicating that her family

\footnotetext{
${ }^{8}$ Because different interviewers conducted the sessions, women may have been asked directly to self-identify their ethnic group or the interviewer may have categorized the women based on language or dress. This inconsistency is a limitation of large-scale survey data in an ethnically divided population.
} 
of origin was Spanish dominant), and who was interviewed in Spanish is considered Ladino and receives a score of three and is classified as Ladino. For the purposes of this analysis, women who were not classified as either fully (for lack of a better term) indigenous (score of zero) or fully Ladino (score of three) are referred to as bicultural (score of either one or two) women as they have traits from both ethnicities.

Including this variable allows for the possibility that a woman could identify as Ladino but could have an indigenous up-bringing as well as for the possibility that a woman could identify as indigenous but, with use of the dominant language, may have increased access to social and health services (Seiber and Bertrand 2002; De Broe et al. 2005; Singh, Prada, and Kestler 2006). In some cases, Spanish speaking women of indigenous heritage have also been linked to different patterns of contraceptive use and fertility than their non-Spanish speaking counterparts (Bertrand, Seiber, and Escudero 2001; De Broe et al. 2005). Based on the previous research and the theories of social and economic marginalization, I anticipate this variable to be positively correlated with both use and intention to use.

Housing Characteristics: This set of variables is used primarily to represent the household economic level and the relative availability and accessibility of health and social services. Economic status has historically been an important component of theoretical models of fertility decline (New Home Economics model (Becker 1981)) and in some applications, the cost of educating children and an increasing focus on material gain have accompanied increases in family size limitation (contraceptive use) (van de Kaa 1996; Rutstein 1998; Bertrand, Seiber, and Escudero 2001). Measuring household income is somewhat complex due to the subsistence lifestyles and inconsistent or seasonal income of many families. Moreover, cultural and rural/urban differences may also impact the expression of household wealth and complicate the selection of a variable capable of capturing economic variability. Therefore different variables representing household assets and economic level and combinations of these variables were initially explored for use in the model. Based on bivariate correlations and confirmed by personal experience in the region, floor material adequately captured economic differences without reliance on a more complicated economic index variable and is therefore used in the analysis. Type of floor material is therefore brought into the model as a measure of household wealth and is divided into two categories, dirt and improved (De Broe et al. 2005). Building on the economic theories, wealthier families - those with developed flooring, have both a greater incentive to limit their families and the financial resources to access potentially costly family planning services.

Television ownership is also incorporated into the model as a potential means of increasing the demand for contraception directly, through family planning information messages, or indirectly through the introduction to Western or more 
urban family size norms and ideals (Sexton 1979; Rutstein 1998; Bertrand et al. 1999; Bertrand, Seiber, and Escudero 2001).

Rates of contraceptive use in Guatemala are higher for women in urban centers (MSPAS 2002). Urban living facilitates women's participation in the labor force and increases educational opportunities (Heaton, Forste, and Otterstrom 2002). Both factors associated with smaller family size goals and increased contraceptive use (Becker 1981; Heaton, Forste, and Otterstrom 2002; Rosero-Bixby, Martin, and Martin-Garcia 2008). Furthermore, urban living may enable the development of influential social-networks useful for passing contraceptive and family planning information which may help to break down social barriers and health concerns relating to family planning implementation (Entwisle et al. 1996; Kohler, Behrman, and Watkins 2001; Lindstrom and Muñoz-Franco 2005; Lindstrom and Hernández 2006; Singh, Prada, and Kestler 2006). To account for the potential differences between urban and rural women, urban residence will be included as a potential splitting variable in the model development.

Because of variation in fertility, contraceptive use rates, and degree of overall development across Guatemala's eight regions, a woman's region of residence may be an important component in her contraceptive use (MSPAS 2002). Moreover, several micro-level studies have evaluated behavior within smaller communities and have revealed significant geographic variation in barriers to contraception (Bertrand, Seiber, and Escudero 2001; De Broe et al. 2005; De Broe and Hinde 2006). Using varying spatial units (municipality, department or regional levels) researchers have linked variation in fertility and family planning behaviors to service access, ethnic diversity and socio-economic level (De Broe and Hinde 2006; Singh, Prada, and Kestler 2006). The results from these studies have not determined the exact mechanisms underlying spatial variation in behaviors, yet they support the importance of incorporating community context in analyses of contraception and childbearing.

Beyond regional variations in behavior, policies impacting health and development are commonly implemented and monitored by the Guatemalan government at the regional level. The Guatemalan government's planning commission $\left(\right.$ SEGEPLAN $\left.^{9}\right)$ is responsible for a broad range of programs and services. The commission functions at a regional level where regional directors and teams work to meet the specific needs of each regional sub-population. This regional approach to service provision and policy implementation further supports the incorporation of region of residence into models of contraceptive behavior.

Family/Relationship Characteristics: Among the variables representing different

${ }^{9}$ La Secretaría de Planificación y Programación de la Presidencia 
aspects of a woman's family and relationship with her partner, the variable t't' union status" is used as a control variable and will be used in the contraceptive use model.

Number of children ever born and number of children who have died are used to represent the "supply" of children in a woman's life. Larger families have been hypothesized to act as a catalyst to increase the demand for contraception (Bertrand et al. 1999; Zaky 2004). However, if the death of a child has occurred, women may be more reluctant to regulate their fertility and would therefore not be expected to use contraception or have an intent to use contraception (Pebley, Delgado, and Brineman 1979).

The final variables in this category were selected to measure the effect of the partner on a woman's intent to use contraception ${ }^{10}$. One of Coale's preconditions of fertility decline states that reduced family size must be seen as beneficial (Coale 1973). However, shared family size aspirations and contraceptive values are not always present within the couple and frequently disagreements result in men making more decisions (Blanc 2001). Women may experience the cost of childbearing to a greater extent than their partners, particularly in gender unequal households, and therefore may have increased contraceptive desire but may not always be able to act on their desires (Fapohunda and Todaro 1988; Dodoo and Seal 1994; Boserup 1981; Dodoo 2001; Carter 2002; 2004). To evaluate household gender power dynamics the number of additional years of education obtained by the partner will be included (Blanc 2001; Speizer, Whittle, and Carter 2005). Where the partner has nearly the same or less education (as indicated by a relatively low value or a value of zero), I anticipate a more equitable partnership which may impact contraceptive intent (Speizer, Whittle, and Carter 2005).

To incorporate the concept of couple's unmet need (Becker 1999) and to evaluate the role of communication ${ }^{11}$ and shared values, the variables giving the respondent's evaluation of contraceptive use agreement in the partnership, her partner's acceptance of family planning, and her partner's desire for more children are also included in the intent to use model.

Researchers have noted that in some cases, predominantly in studies of African

${ }_{10}$ Partner characteristics are only explored in the intent to use model, as this portion of the analysis is restricted to women in union.

${ }^{11}$ Intercouple communication is difficult to measure in quantitative surveys. Of the limited research exploring surveyed responses to communication questions like those used in this analysis, concerns over the validity of these variables in capturing the actual communication - both verbal and non-verbal - have arisen.

However, the responses to intercouple communication questions are used by policy makers and health professionals as they develop contemporary family planning outreach strategies that seek to include the partner (DeRose et al. 2004). It is therefore important to explore these variables to determine their relationship to both the response and predictor variables. Ideally, qualitative research will be guided by the results of this study and related studies and will contribute to an even greater understanding of the role of the partner in contraceptive use and fertility. 
countries, women report non-use of contraception because of partner disapproval (DeRose et al. 2004). The general assumption is that increasing inter-couple communication of contraception and childbearing will lead to increased contraceptive use and may help to combat partner disapproval of fertility regulation (DeRose et al. 2004). However, it is not clear if these discussions or the partner's opinion actually have a notable impact on behavior in Guatemala. Including results from these questions in the models allows for direct analysis of the impact of the partner's preferences and the couple's communication on contraceptive intent. Before this study, no analysis of Guatemalan reproductive behavior had included these variables. The results of this portion of the analysis will therefore enhance understanding of the role of the couple in determining contraceptive demand.

\section{Results}

\subsection{Descriptive analysis}

The rates, means and standard errors of each of the independent variables are presented in terms of the ethnicity variable (Table 1). Of the 7,851 women who are included in the analysis in the 2002 period (infecund , menopausal or sterile, and those who are pregnant were excluded from the analysis), the majority (67\%) are Ladino. The ethnicity variable generally partitions the women identified as indigenous based on their language skills. Sixty-seven women who are identified (through either self-identification or interviewer identification) in the RHS as Ladino did not interview in Spanish and their maternal language was not Spanish. The majority of the bicultural women (see Table 2) were identified as indigenous (and would normally be classified as indigenous if only two ethnic categories were employed) with Ladino language characteristics. Average age was fairly consistent across the population (roughly 27-29 years). Education levels, however are quite varied. As compared to the Ladino women, the indigenous women had much lower levels of secondary education. Approximately 5\% of indigenous women reported that they received a secondary or beyond secondary education as compared to $43 \%$ of the Ladino women. Increasing rates of primary and secondary education occur as we move away from the fully indigenous women to the fully Ladino women ${ }^{12}$.

12 Based on 2002 population census levels, it is likely that rates of non-educated indigenous women are much higher than those indicated by the 2002 RHS. Approximately two thirds of the indigenous women questioned for the RHS did not record a level of education and may explain the apparently large increase in indigenous women attaining at least some education. The large differences between the survey based education estimates and the census based estimates is likely a result of differences in indigenous classification, treatment of missing data (perhaps a response of 'no education' for surveyed participants was recorded as a missing value), or possibly a different strategy used for estimating educational attainment. Regardless of the source of the discrepancies, however, indigenous education indicators should be interpreted with care. 
Table 1: Descriptive statistics for variables included in the analysis

\begin{tabular}{|c|c|c|c|}
\hline & Indigenous & Bicultural & Ladino \\
\hline Count & 1004 & 1593 & 5254 \\
\hline Percent of country total & $12.8 \%$ & $20.3 \%$ & $66.9 \%$ \\
\hline Interview language (Spanish) & $0.0 \%$ & $99.5 \%$ & $100.0 \%$ \\
\hline Maternal language (Spanish) & $0.0 \%$ & $25.1 \%$ & $100.0 \%$ \\
\hline Ethnic identification (Ladino) & $0.0 \%$ & $4.6 \%$ & $100.0 \%$ \\
\hline Mean age (standard deviation) & $\begin{array}{c}28.57 \\
(9.6)\end{array}$ & $\begin{array}{c}27.64 \\
(9.8)\end{array}$ & $\begin{array}{c}28.98 \\
(10.0)\end{array}$ \\
\hline \multicolumn{4}{|l|}{ Level of education } \\
\hline None & $4.7 \%$ & $3.5 \%$ & $1.9 \%$ \\
\hline Primary & $89.9 \%$ & $76.1 \%$ & $54.7 \%$ \\
\hline Secondary (plus) & $5.4 \%$ & $20.4 \%$ & $43.4 \%$ \\
\hline \multicolumn{4}{|l|}{ Religion } \\
\hline Catholic & $54.3 \%$ & $49.0 \%$ & $49.7 \%$ \\
\hline \multicolumn{4}{|l|}{ Housing characteristics } \\
\hline \multicolumn{4}{|l|}{ Region } \\
\hline Metropolitan & $1.3 \%$ & $26.4 \%$ & $43.5 \%$ \\
\hline North & $36.8 \%$ & $8.5 \%$ & $1.6 \%$ \\
\hline Northeast & $6.4 \%$ & $1.8 \%$ & $9.7 \%$ \\
\hline Southeast & $0.0 \%$ & $0.8 \%$ & $12.8 \%$ \\
\hline Central & $2.2 \%$ & $12.4 \%$ & $11.2 \%$ \\
\hline Southwest & $22.8 \%$ & $30.0 \%$ & $13.7 \%$ \\
\hline Northwest & $25.9 \%$ & $18.3 \%$ & $4.4 \%$ \\
\hline Petén & $4.7 \%$ & $1.9 \%$ & $3.0 \%$ \\
\hline \multicolumn{4}{|l|}{ Area } \\
\hline Urban & $8.0 \%$ & $40.4 \%$ & $47.0 \%$ \\
\hline \multicolumn{4}{|l|}{ Type of floor material } \\
\hline Dirt & $84.3 \%$ & $53.1 \%$ & $27.1 \%$ \\
\hline \multicolumn{4}{|l|}{ Own television } \\
\hline Yes & $17.1 \%$ & $55.9 \%$ & $79.4 \%$ \\
\hline \multicolumn{4}{|l|}{ Family/Relationship characteristics } \\
\hline 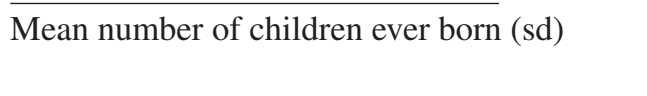 & $\begin{array}{r}3.97 \\
(3.5)\end{array}$ & $\begin{array}{c}3.02 \\
(3.3)\end{array}$ & $\begin{array}{c}2.43 \\
(2.5)\end{array}$ \\
\hline Mean number of children who have died (sd) & $\begin{array}{c}0.45 \\
(1.0)\end{array}$ & $\begin{array}{l}0.15 \\
(.5)\end{array}$ & $\begin{array}{l}0.15 \\
(.5)\end{array}$ \\
\hline
\end{tabular}


Grace: Contraceptive use and intent in Guatemala

Table 1: $\quad$ (Continued)

\section{Indigenous Bicultural Ladino}

\section{Partner Variables}

In Union

Yes

Agreement about methods

Yes

$72.9 \%$

$61.4 \%$

$60.3 \%$

No

$50.8 \%$

$57.1 \%$

$84.4 \%$

$23.8 \%$

$21.5 \%$

$9.5 \%$

No opinion

$25.4 \%$

$21.5 \%$

$6.2 \%$

Partner supports family planning

Yes

$41.8 \%$

$52.2 \%$

$79.7 \%$

No

$27.8 \%$

$22.2 \%$

$12.1 \%$

Don't know

$30.4 \%$

$25.6 \%$

$8.2 \%$

Women/Partner child preference

Same number

$57.4 \%$

$48.0 \%$

$71.4 \%$

More children

$12.6 \%$

$10.1 \%$

$11.9 \%$

Fewer children

$5.5 \%$

$7.1 \%$

$8.6 \%$

Don't know

$24.5 \%$

$34.8 \%$

$8.2 \%$

Mean woman/Partner years of ed. diff. (sd)*

1.17

Response Variables

Intent to Use** (yes)

$37.4 \%$

$54.0 \%$

$47.9 \%$

Modern Method Use

Note: Author's calculations based on data from the 2002 RHS. The first five rows of the table present the ethnicity variable and highlight the breakdown within each ethnic category by language and ethnic identification. The remainder of the table presents means (with standard deviations) and percentages for each variable within each category.

* This information was only available for 3327 couples.

** This is calculated only for non-contracepting women in partnerships. 
Table 2: $\quad$ Breakdown of bicultural classification

\begin{tabular}{lllr}
\hline Self-identification & Interview language & Maternal language & Count \\
\hline Ladino & Mayan-based & Mayan-based & 6 \\
& Spanish & Mayan-based & 67 \\
& Mayan-based & Spanish & 0 \\
\hline Indigenous & Spanish & Spanish & 398 \\
& Mayan-based & Spanish & 2 \\
& Spanish & Mayan-based & 1120
\end{tabular}

Note: Author's calculations based on data from the 2002 RHS.

The majority of women who live in the Metropolitan, Southeast and Northeast regions were Ladino. Of the non-Ladino women in the Metropolitan region, the majority have some Spanish language skills. The largest percentage of the indigenous live in the Northern region while the Southwest and Northwest regions have high percentages of both indigenous and bicultural women. Among the women grouped into non-Ladino, the majority lived in rural areas with the largest differential in urban/rural dwelling among the fully indigenous women. The proportion of fully Ladino women living in rural areas was almost equal to those living in urban areas. Enhanced or developed flooring and television ownership were more characteristic of Ladino women than indigenous women. Therefore, based on socio-demographic characteristics and consistent with previous research, non-Spanish speaking women are generally worse off, in terms of economic and education status, than Ladino women.

In terms of couple/partner characteristics, the majority of Ladino women were in partnerships where the couple agreed on methods, the partner supports family planning, and the couple had shared family size goals. Indigenous and non-Spanish speaking women report lower rates of agreement and partner family planning support than Ladino women. They also report lower rates of family size preference agreement. Given that some research has documented the significant role of men and men's attitudes towards contraceptive use, individual differences in use behavior and intent based on ethnicity may be capturing the impact of the partner. Therefore, instead of using ethnicity or cultural differences to explain differences in contraceptive use/intent, partner or couple characteristics could be used to explain some of the variation in behavior.

The final rows of Table 1 provide the descriptive information of the response variables. Modern method use was increasingly common among the Ladino women, contrasting with very low rates of use among the indigenous population. Among women who do not use contraception, intent to use rates are lowest for indigenous women and highest for the 
bicultural women. The majority of Ladino and indigenous non-users, however, have no intent to use contraception.

\subsection{Trees}

Trees were constructed to determine populations at most need for contraception and family planning services. The two dependent variables, use versus non use ${ }^{13}$ and intent versus no-intent were used to build trees for the entire Guatemalan population.

In the tree presentations used here the dependent variable most effective at splitting the data (the variable that produces the most pure nodes as a sum of the Gini coefficient values calculated for each node) is then listed, followed by the next variable, and so on. At each terminal node, representing a homogenous sub-population such that no additional splitting is necessary, a box with the response variable and the corresponding prevalence in the sub-population is listed. If the percentage of users or intenders is greater than fifty then the terminal node is shaded pink, otherwise the terminal node is shaded grey. Note that trees do not indicate a variable hierarchy and that each terminal node represents an at-risk (or at-need) group of the overall population. The thickness of the lines linking each node represents the size of the population characterized by the variable values and the number of women characterized by each variable is listed above the branches. Regions ${ }^{14}$ are referred to in the tree by letter (see Figure 3 for a Guatemala map and a key to the letter codes).

The modern use tree, Figure 1, highlights the importance of the number of children, economic status (flooring), marital status, region of residence, ethnicity and age. The $4.7 \%$ use rate among women with none or high numbers of children is significantly lower than the population use rate of $31.2 \%$. This sub-population likely contains the large number of adolescents who have entered into sexual relationships but are not yet using contraception. Contraceptive use among adolescents and young adults is relatively low, particularly among those who are not in an established union (Figueroa et al. 2006).

Beyond parity, economic status and marital status further disaggregate the sample data. Wealthier women who are not in union have a use rate of $32.4 \%$. Wealthier women in union who are non-Spanish speaking and have an indigenous maternal language and who live in the North, Northwest, Southeast and Southwest regions have a lower use rate $(18.1 \%)$ than the overall sample population. In contrast, one of the largest sub-populations

${ }_{13}$ Use is restricted to women using modern methods. Too few women were traditional contraceptive users as compared to modern users and non-users. Multinomial and tree models using a three pronged usage variable showed no difference in variable selection as compared to the two pronged variable used here.

14 The division of Guatemala into eight policy and statistical regions is well established among governmental agencies. Regions serve as the largest geographic level of policy implementation and statistical data collection and analysis. 
of higher-income women - those who are in union, live in North, Northwest, Southeast and Southwest regions, speak Spanish, and are between the ages of 25 and 49 - report the highest contraceptive use rate $-66.2 \%$. The primary difference between these two groups of women, those with a use rate of $18.1 \%$ and those with a use rate of $66.2 \%$, is language. This result supports the need for multi-lingual service provision within these regions.

\section{Figure 1: $\quad$ Tree of contraceptive use versus non-use among Guatemalan women in 2002}

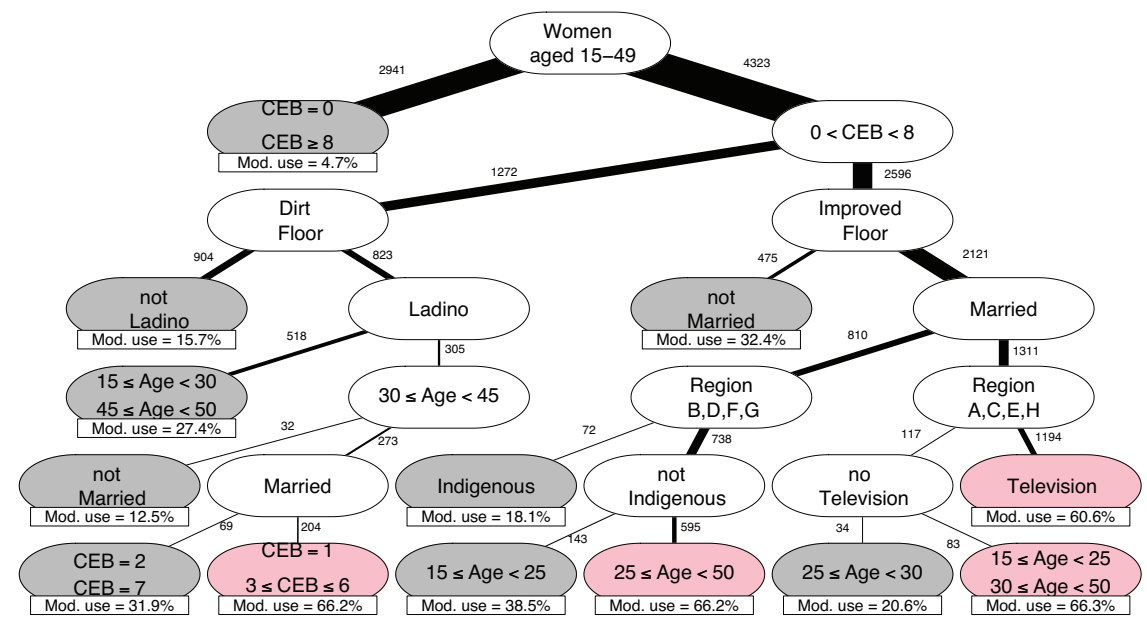

Note: Author's calculations based on equally weighted sample from 2002 RHS data. The rate of contraceptive use in the population before any splits is $31.2 \%$. Width of the lines represents the proportion of the population meeting the nodal characteristic. Thicker lines indicate that a larger portion of the population was classified by the specific variable category. The shaded ovals represent terminal nodes beyond which the population cannot be efficiently split. The boxes below the terminal nodes present the proportion of contraceptive users in the specific sub-population. Region codes are found in Figure 3.

Women of low economic status, those with dirt flooring, report the highest use rates $(66.2 \%)$ if they are Ladino, in union, in the middle of the age range and have a specific number of children ( 1 or between 3 and 6 ). This rate is in contrast to the much lower rates among the large sample of non-Ladino women (15.7\%), younger and older women $(27.4 \%)$ and single women $(12.5 \%)$. Therefore, these results highlight the specific sub-groups of need among the more impoverished women in Guatemala - 
the indigenous/bicultural population, those at the beginning or nearing the end of their childbearing and those who are not in union.

Figure 2 present the results from the country-wide intent tree. The tree splits first on couple's agreement on contraceptive methods. When the couple does not agree on methods, according to the surveyed response of the woman, the sub-population has virtually no intent to use contraception (11.6\%). While the limitations of this measurement are known, clearly the role of the partner in determining future contraceptive use is important. More research into the role of the male partner in the decision making process is needed but it may be worthwhile to include men in family planning outreach and education strategies increasing intent and demand. Among those who are in agreement with their partner, age is a determining factor (younger women have a 74.7\% rate of intent). Ensuring that family planning information and services are available to the older cohort of women may therefore have important impacts on contraceptive intent and demand. 
Figure 2: $\quad$ Tree of intent to use contraception versus no-intent to use among Guatemalan women in 2002

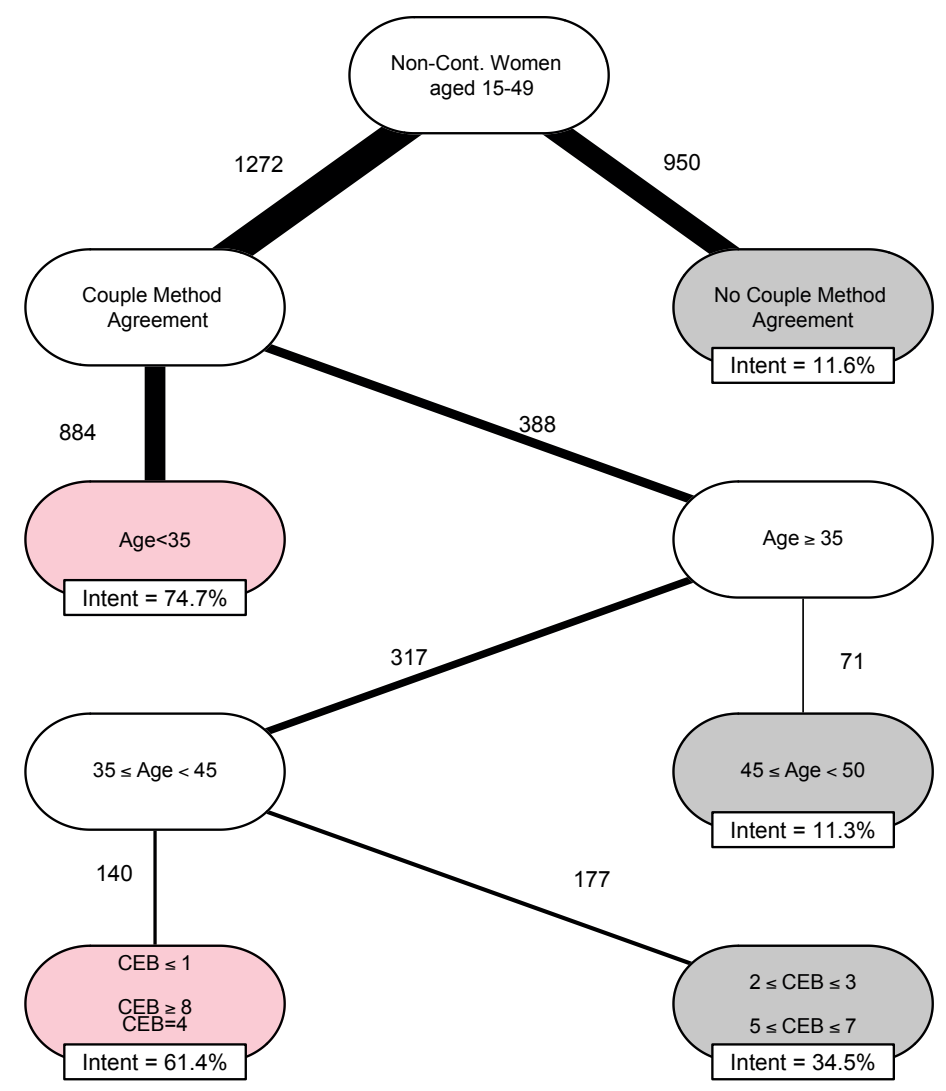

Note: Author's calculations based on equally weighted sample from 2002 RHS data. The rate of intent to use in the population before any splits is $41.6 \%$. Width of the lines represents the proportion of the population meeting the nodal characteristic. Thicker lines indicate that a larger portion of the population was classified by the specific variable category. The shaded ovals represent terminal nodes beyond which the population cannot be efficiently split. The boxes below the terminal nodes present the proportion of women with intent to use in the specific sub-population. Region codes are found in Figure 3. 
Grace: Contraceptive use and intent in Guatemala

Figure 3: Guatemala map with region names and codes

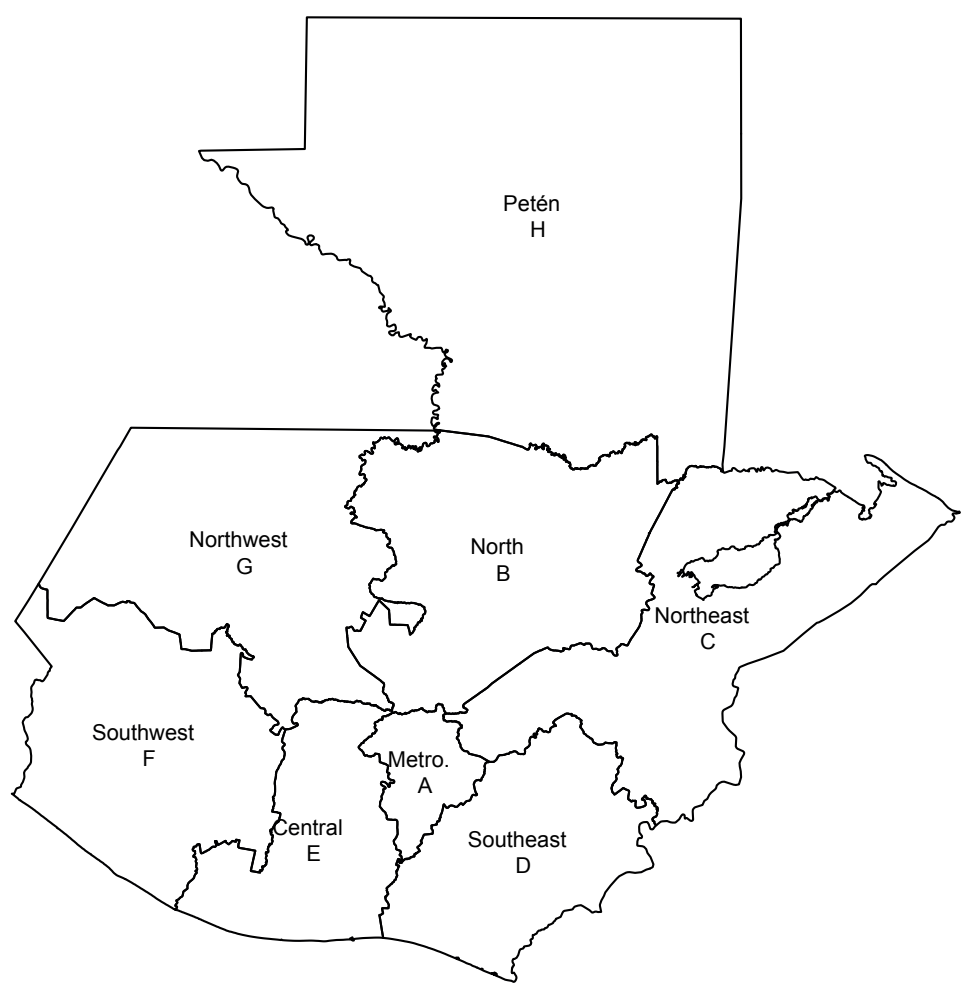




\section{Discussion}

Contraceptive use: The primary objective of this research was to identify characteristics associated with women who have the most need for contraceptive and family planning services. The use of classification modeling techniques highlighted populations that are at particular need for services. The tree of modern contraceptive use, which includes a measure of household wealth as a splitting variable, suggests that fewer poor women use contraception as compared to wealthier women. In combination with ethnicity, poor indigenous and bicultural women stand out with particularly low use rates. Since bicultural women (the large majority of whom speak Spanish) are grouped (by the classification approach) with non-Spanish speaking indigenous women, we cannot conclude that language alone serves as a barrier to contraceptive use among the poorest women (Terborgh et al. 1995; Santiso-Galvez and Bertrand 2004; De Broe et al. 2005; De Broe and Hinde 2006). Instead, in combination with low economic status, the model either indicates that indigenous and bicultural women have reduced interest in planning their families or that among indigenous and bicultural women economic status serves as a barrier to family planning access and use (Becker 1981; Monteith et al. 1985; Terborgh et al. 1995; Bertrand, Seiber, and Escudero 2001). However, among Ladino women economic status does not appear to serve as the barrier to contraceptive use that it does for indigenous women. Young Ladino women and Ladino women nearing the end of their reproductive years or women with large numbers of children show increasing use of modern contraception despite their comparatively limited financial means.

Among the wealthier sub-population differences persist in contraceptive use across linguistic more than ethnic barriers. The fact that women who speak Spanish, regardless of a possible indigenous heritage, are using contraception more than their non-Spanish speaking neighbors suggests that in some regions of the country (particularly those that are the most heavily indigenous), language acts as a barrier to services. Considering these results and the significance of both language and cultural heritage for both wealthy and poor women, family planning strategies addressing the linguistic, and in some cases, the cultural differences of indigenous women would likely have a noticeable impact on contraceptive use. Furthermore, a closer look at the quality of services available to indigenous and bicultural women, including the presence of a readily available bilingual health practitioner, may provide insight into the low use rates and indicate future directions for improved family planning services (Seiber and Bertrand 2002; Singh, Prada, and Kestler 2006).

Intent to use: Of the few studies that have examined correlates or determinants of contraceptive intentions, nearly all have determined that contraceptive use and intent share most of the same demographic, cultural and economic factors (Curtis and Westoff 1996). Curtis and Westoff (1996) suggest that the similarities in models predicting use 
or intention may be attributable to the order of the decision-making process - intention naturally precedes use and therefore those women who use contraception also intended to use before they actually began using contraception. However, the results presented in this research reveal some differences in factors correlated to the response variables. We cannot directly compare the intent and use trees because the samples analyzed are not identical, but we can explore the implications of the results. In terms of women who are not using contraception but intend to at some point, the role of the partner is important in determining contraceptive intent (Carter 2002; 2004). This may indicate lack of equal-power domestic relationships or it may simply indicate couple-based decision-making as a component of family planning use. It is also possible that the partner selection occurs after a woman has already made the decision to use (or not use) contraception and then selects a like minded partner.

While it is apparent that the low level of the intent to use rate clearly reflects the attitudes of both partners, to determine if the low rate reflects low demand or barriers to services (which could result because of the partner's attitude) however, more research needs to be done on the role of the partner selection process and the role the partner plays in couple-level contraceptive use. Furthermore the differences in partner attitudes and couple characteristics may reflect ethnic differences, as evidenced in the descriptive table, and should motivate more in depth research into family and gender dynamics within the different ethnic groups in Guatemala. Qualitative research evaluating the family planning decision making process with regard to ethnicity, partner selection and the timing of childbearing would provide important insight into contraceptive practices in Guatemala and would likely improve the allocation of family planning services and outreach.

The Role of Education: Despite the significance of education level or years of education found in related research, this variable was not found to be significant in this analysis. In fact, education level is absent from both intent and use trees. While the descriptive table demonstrates the significant differences in educational attainment across ethnicities and related research has highlighted differences in contraceptive use and demand across educational strata, we do not see these results in the trees. There is no indication that family planning outreach and programs should target the less educated more than the highly educated; instead we see differences in use and intent based on economic and cultural differences. The exclusion of education level from the models likely highlights the differences between ethnic and economic groups that are generally represented as educational differences in other research of Guatemalan contraceptive patterns (Bertrand, Seiber, and Escudero 2001; Seiber and Bertrand 2002; De Broe and Hinde 2006). These results suggest that the significance of education in related regression-based research results specifically accounts for economic and cultural differences rather than a direct effect of education.

Ultimately, the trees highlight that educational expansion among Guatemalan women 
will likely only have an impact on family planning behaviors when cultural and economic divides are also addressed. Further research into educational barriers among the poor and non-Spanish speaking will be helpful in further understanding the challenges facing educational expansion in Guatemala. More broadly, the non-significance of the education variable calls into question the role of education in contemporary theories of fertility decline and change. It is not generally clear in much of the contemporary research whether education indirectly measures cultural values, economic status, or if it directly delays intercourse and partnership formations that would lead to childbearing. This research, however, suggests that when economic and cultural factors are accounted for, women's education may have little to do with the variation in reproductive health and fertility.

Place - Region of residence: Reflecting the Guatemalan government's use of eight policy and statistical regions, region of residence was included in the analysis as an independent variable. The significance of region of residence underscores the importance of "place" in family planning. For example, in the contraceptive use tree (Figure 1) the model splits on region of residence after several splits on socio-demographic variables. A large portion of the population of married women, as indicated by the thickness of the branch through the nodes, have different patterns of use simply because of their home region. While the trees do not indicate any need to target urban women differently than rural women, they do highlight the significance of regional differences. The post-region splits suggest that factors such as ethnicity, age and television ownership are significant only for women in specific regions of the country. Practically, these results call for regionally-designed family planning services and, in some cases, those services specifically catering to non-Spanish speaking women or to younger women according to the needs of the region's residents. Theoretically, the significance of region of residence encourages researchers to incorporate the characteristics of the community and the surrounding areas and to consider the individual as a member of a larger community network when evaluating fertility and family planning in developing countries.

\section{Conclusion}

Combining the results from the each tree supports the continued expansion of reproductive health services to poor women and indigenous women. The fact that indigenous women with Spanish language skills were sometimes grouped with their non-Spanish speaking indigenous counterparts suggests that continued research and outreach addressing the specific indigenous cultural barriers to family planning could assist in increasing contraceptive use, access and demand. The significance of region of residence after adjusting for individual socio-demographic characteristics encourages region-specific reproductive health outreach and implementation strategies. Finally, including men in 
family planning education and encouraging their commitment to the health and well-being of their partners and families could also lead to an increase in contraceptive use and a decrease in unplanned or mistimed pregnancies. In sum, the development of outreach and education strategies addressing individual contraceptive use decision-making and accessibility issues will likely lead to improvements in health resource allocation and the overall health of Guatemalans.

\section{Acknowledgments}

Research assistance and comments from Stuart Sweeney, Jude Mikal and Eliza Bradley and comments from Paula Tavrow, James Holland Jones, Joshua Goldstein, Andrew Hinde and two anonymous reviewers are gratefully acknowledged. Also thanks to the Centers for Disease Control and Paul Stupp and Alicia Ruiz for providing the 2002 Reproductive Health Survey data. 


\section{References}

Ambalavanan, N., Baibergenova, A., Carlo, W.A., Saigal, S., Schmidt, B., and Thorpe, K.E. (2006). Early prediction of poor outcome in extremely low birth weight infants by classification tree analysis. The Journal of Pediatrics 148(4): 438-444. doi:10.1016/j.jpeds.2005.11.042.

Anderson, J.E., Morris, L., Pineda, A., and Santiso, R. (1980). Determinants of fertility in Guatemala. Social Biology 27(1): 20-35.

Becker, G.S. (1981). A Treatise on the Family. Cambridge, MA: Harvard University Press.

Becker, S. (1999). Measuring unmet need: Wives, husbands or couples? International Family Planning Perspectives 25(4): 172-180. doi:10.2307/2991881.

Bertrand, J., de Salazar, S.G., Mazariegos, L., Salanic, V., Rice, J., and Sow, C.K. (1999). Promoting birthspacing among the Maya-Quiche of Guatemala. International Family Planning Perspectives 25(4): 160-167. doi:10.2307/2991879.

Bertrand, J.T., Seiber, E., and Escudero, G. (2001). Contraceptive dynamics in Guatemala: 1978-1998. International Family Planning Perspectives 27(3): 112-118 + 136. doi:10.2307/2673832.

Blanc, A.K. (2001). The effect of power in sexual relationships on sexual and reproductive health: An examination of the evidence. Studies in Family Planning 32(3): 189-213. doi:10.1111/j.1728-4465.2001.00189.x.

Boserup, E. (1981). Population and Technological Change: A Study of Long-Term Trends. Chicago: University of Chicago Press.

Carter, M.W. (2002). 'Because he loves me': Husbands' involvement in maternal health in Guatemala. Culture, Health \& Sexuality 4(3): 259-279. doi:10.1080/13691050110112784.

Carter, M.W. (2004). Gender and community context: An analysis of husbands' household authority in rural Guatemala. Sociological Forum 19(4): 633-652. doi:10.1007/s11206-004-0699-0.

Coale, A.J. (1973). The demographic transition. In: Proceedings of the IUSSP International Population Conference, Liége, 1973. Liége: International Union for the Scientific Study of Population: 53-72.

Curtis, S.L. and Westoff, C.F. (1996). Intention to use contraceptives and subsequent contraceptive behavior in Morocco. Studies in Family Planning 27(5): 239-250. 
doi: $10.2307 / 2137996$.

Cutright, P., Hout, M., and Johnson, D.R. (1976). Structural determinants of fertility in Latin America: 1800-1970. American Sociological Review 41(3): 511-527. doi: $10.2307 / 2094257$.

De Broe, S. and Hinde, A. (2006). Diversity in fertility patterns in Guatemala. Population, Space and Place 12(6): 435-459. doi:10.1002/psp.413.

De Broe, S., Hinde, A., Matthews, Z., and Padmadas, S.S. (2005). Diversity in family planning use among ethnic groups in Guatemala. Journal of Biosocial Science 37(3): 301-317. doi:10.1017/S0021932004006650.

DeRose, L.F., Dodoo, F.N., Ezeh, A.C., and Owuor, T.O. (2004). Does discussion of family planning improve knowledge of partner's attitude toward contraceptives. International Family Planning Perspectives 30(2): 87-93. doi:10.1363/3008704.

Dodoo, F.N. (2001). Fertility preference and contraceptive use: A profitable nexus for understanding the prospects for fertility decline in Africa. New York: Population Division, Department of Economic and Social Affairs, UN Secretarial.

Dodoo, F.N. and Seal, A. (1994). Explaining spousal differences in reproductive preferences: A gender inequality approach. Population and Environment 15(5): 379-394. doi:10.1007/BF02208319.

Entwisle, B., Rindfuss, R.R., Guilkey, D.K., Chamratrithirong, A., Curran, S.R., and Sawangdee, Y. (1996). Community and contraceptive choice in rural Thailand: A case study of Nang Rong. Demography 33(1): 1-11. doi:10.2307/2061709.

Fapohunda, E.R. and Todaro, M.P. (1988). Family structure, implicit contracts, and the demand for children in southern Nigeria. Population and Development Review 14: 571-596. doi:10.2307/1973625.

Faraway, J. (2006). Extending the Linear Model with R: generalized linear, mixed effects and non-parametric regression models. Chapman \& Hall.

Figueroa, W., Lopez, F., Remez, L., Prada, E., and Drescher, J. (2006). Early childbearing in Guatemala: A continuing challenge. Alan Guttmacher Institute. (Issues In Brief 5: $1-20)$.

Grace, K. and Sweeney, S. (2009). Informal and Formal Union Formation in Three Central American Countries. Paper presented at the 2009 Population Association Annual Meeting, Detroit, April 30-May 2, 2009.

Hall, M.F. (1973). Population growth: U.S. and Latin American views: An interpretation 
of the response of the United States and Latin America to the Latin American population growth. Population Studies 27(3): 415-429. doi:10.2307/2173762.

Heaton, T.B., Forste, R., and Otterstrom, S.M. (2002). Family transitions in Latin America: First intercourse, first union and first birth. International Journal of Population Geography 8(1): 1-15. doi:10.1002/ijpg.234.

Herold, J.M., Westoff, C.F., Warren, C.W., and Seltzer, J. (1989). Catholicism and fertility in Puerto Rico. American Journal of Public Health 79(9): 1258-1262. doi:10.2105/AJPH.79.9.1258.

Kohler, H., Behrman, J.R., and Watkins, S.C. (2001). The density of social networks and fertility decisions: Evidence from South Nyanza District, Kenya. Demography 38(1): 43-58. doi:10.1353/dem.2001.0005.

Lemon, S.C., Roy, J., Clark, M.A., Friedman, P.D., and Rakowski, W. (2003). Classification and regression tree analysis in public health: Methodological review and comparison with logistic regression. Annals of Behavioral Medicine 26(3): 172-181. doi:10.1207/S15324796ABM2603_02.

Lindstrom, D.P. and Muñoz-Franco, E. (2005). Migration and diffusion of modern contraceptive knowledge and use in rural Guatelama. Studies in Family Planning 36(4): 277-288. doi:10.1111/j.1728-4465.2005.00070.x.

Lindstrom, D.P. and Hernández, C.H. (2006). Internal migration and contraceptive knowledge and use in Guatemala. International Family Planning Perspectives 32(3): 146-153. doi:10.1363/3214606.

Martin, M.A., Meyricke, R., O'Neill, T., and Roberts, S. (2006). Mastectomy or breast conserving surgery? Factors affecting type of surgical treatment for breast cancer - a classification tree approach. BMC Cancer 6(98). doi:10.1186/1471-2407-6-98.

Martine, G. (1996). Brazil's fertility decline, 1965-95: A fresh look at key factors. Population and Development Review 22(1): 47-75. doi:10.2307/2137686.

McQuillan, K. (2004). When does religion influence fertility? Population and Development Review 30(1): 25-56. doi:10.1111/j.1728-4457.2004.00002.x.

Monteith, R.S., Anderson, J.E., Pineda, M.A., Santiso, R., and Oberle, M. (1985). Contraceptive use and fertility in Guatemala. Studies in Family Planning 16(5): 279-288. doi:10.2307/1967001.

MSPAS (2002). Guatemala: Encuesta nacional de salud materno infantile 2002 informe final. Ministerio de Salud Publica y Asistencia Social (MSPAS), Instituto Nacional de Estadistica (INE) and Centers for Disease Control (CDC). 
Nelson, L.M., Bloch, D.A., Longsteth, W.T., and Shi, H. (1998). Recursive partitioning for the identification of disease risk subgroups: a case-control study of subarachnoid hemorrage. Journal of Clinical Epidemiology 51(3): 199-209. doi:10.1016/S0895-4356(97)00268-0.

Pebley, A.R., Delgado, H., and Brineman, E. (1979). Fertility desires and child mortality experience among Guatemalan women. Studies in Family Planning 10(4): 129-136. doi: $10.2307 / 1965691$.

Pebley, A.R., Goldman, N., and Robles, A. (2005). Isolation, integration, and ethnic boundaries in rural Guatemala. The Sociological Quarterly 46(2): 213-236. doi:10.1111/j.1533-8525.2005.00010.x.

PRB (2007). World population data sheet. Population Reference Bureau.

Rosero-Bixby, L., Martin, T.C., and Martin-Garcia, T. (2008). Is Latin America starting to retreat from early and universal childbearing? Paper presented at the 2008 Annual Meeting of the Population Association of America Conference, New Orleans, USA, April 17-19, 2008.

Rutstein, S.O. (1998). Change in the desired number of children: A cross-country cohort analysis of levels and correlates of change. Calverton, Maryland: Macro International Inc. (Technical Report AR9).

Santiso-Galvez, R. and Bertrand, J.T. (2004). The delayed contraceptive revolution in Guatemala. Human Organization 63(1): 57-67.

Seiber, E.E. and Bertrand, J.T. (2002). Access as a factor in differential contraceptive use between Mayans and ladinos in Guatemala. Health Policy and Planning 17(2): 167-177. doi:10.1093/heapol/17.2.167.

Sexton, J.D. (1979). Education and acculturation in highland Guatemala. Anthropolgy and Education Quarterly 10(2): 80-95. doi:10.1525/aeq.1979.10.2.05x1224b.

Shah, N.M., Shah, M.A., and Radovanovic, Z. (1998). Patterns of desired fertility and contraceptive use in Kuwait. International Family Planning Perspectives 24(3): 133-138. doi:10.2307/3038210.

Singh, S., Prada, E., and Kestler, E. (2006). Induced abortion and unintended pregnancy in Guatemala. International Family Planning Perspectives 32(3): 136-145. doi: $10.1363 / 3213606$.

Speizer, I.S., Whittle, L., and Carter, M. (2005). Gender relations and reproductive decision making in Honduras. International Family Planning Perspectives 31(3): 131-139. doi:10.1363/3113105. 
Terborgh, A., Rosen, J.E., Galvez, R.S., Terceros, W., Bertrand, J.T., and Bull, S.E. (1995). Family planning among indigenous populations in Latin America. International Family Planning Perspectives 21(4): 143-149 + 166. doi: $10.2307 / 2133321$.

van de Kaa, D.J. (1996). Anchored narratives: The story and findings of half a century of research into determinants of fertility. Population Studies 50(3): 389-432. doi:10.1080/0032472031000149546.

Wilson, R. (1999). Maya Resurgence in Guatemala: Q'Eqchi' Experiences. University of Oklahoma Press.

Zaky, H.H.M. (2004). Fertility transition and female rational choices in Egypt. Journal of Health and Population in Developing Countries 5 May, 2004. http://www.jhpdc.unc.edu. 
Grace: Contraceptive use and intent in Guatemala 